\section{BARE BONES OF HEREDITY}

\section{Towards an Understanding of the Mechanism of Heredity}

By H. L. K. Whitehouse. Pp. xii $+372+4$ plates. (London: Edward Arnold (Publishers), Ltd., 1965.) $55 s$. net.

$7 \mathrm{HE}$ problem of presenting genetics has radically changed in the past 10 years. Formerly, the subject having become the connecting framework of biology, the most obvious requirement was to explain its connectedness. This task was fairly straightforward. A common chemical basis for heredity, certain universal principles of differentiation, processes of evolution experimentally demonstrated, a mechanism known to control differentiation and evolution and also to be subject to them, these together offered us a wide choice of connected treatments.

To-day the task is more complicated. New mechanisms of heredity have been discovered which are understood at different levels and with different degrees of exactness. Their evolutionary connexion is not yet fully clear. Their chemical relationship is uneertain. Their physiological scope, owing to the range of size betwcen bacteria and the higher organisms, is sharply contrasted. 'The experimental evidence in the new fields is fragmentary and sporadic. We may give the name of chromosomes to the structures responsible for heredity in all organisms. And we may agree that they are all based on DNA. But we also know that the organization of tho DNA is of different kinds and the mechanisms which they operate may therefore vary in character.

In these circumstances an attempt to present the whole story in one volume is bound to seem hazardous and even heroic. Dr. Whitehouse has understood this and has attempted to get round the difficulties by a radically new approach. Let us, he says in effect, put crossing over in the centre of the field and let us try to separate the mechanism of heredity from its biological background. Let us in this way cut out the evolutionary and physiological trimmings and show the bare bones of the subject.

How does the method work? Undoubtedly the result provides a review and an interpretation of the whole subject, unified, documented and illustrated, in the way a research worker needs. The account proceeds in historical order of study, beginning mainly with the higher organisms. Here, outside the field of crcssing over, Whitehouse refers to gene action, nuclear-cytoplasmic reactions, plastid inheritance, sex determination, and the induction and analysis of mutation. Within the field of crossing over he discusses some of the consequences of structural hybridity. $\mathrm{H}_{e}$ sacrifices genotypic control and its relation to the breeding system, which is a pity as they throw light on several aspects of the strictly mechanical problem. Also at this point he makes one commonly repeated mistake, derived probably from Morgan. He refers to Janssens as supposing that the structure of a chiasma and the event of crossing over had one character, one origin and one connexion. In fact Janssens' theory was not this at all. He assumed every conceivable kind of character, origin and connexion for them; and one of his assumptions for the connexion we now believe to have been correct.

It is in the fields of micro-organisms, however, that Whitehouse comes to grips with the problem of crossing over on the chemical level and makes his own original interpretations. Here he meets the difficulty of reconciling his views of micro-organisms with the properties of chromosomes in the higher organisms. He overcomes it by supposing that the chromosomes of the higher organisms are composed of single DNA molecules. The known variations in the size of chromosomes and of their DNA contents, however, do not allow this view.

They are usually multiples; they are also variable multiples; and the degree and timing of their multiplica- tion, as recent observations have shown, vary under genotypic control. The multiple (or polynemic) DNA molecule creates several theoretical difficulties. It not only excludes Dr. Whitehouse's attempt to reconcile chromosome structure in different classes of organisms; it also, as was realized 30 years ago, introduces problems for the theory of gene mutation. But we must not think we can reach quick conclusions by ignoring a part of the evidenee.

These are examples of the kind of questions, new and old, that will arise from reading Dr. Whitehouse's book. And his book will have to be read by those who want to answer them.

C. 1). DARLingtox

\section{TWO VIEWS ON INSECTS}

\section{Basic Arthropodan Stock with Special Reference to Insects}

By A. G. Sharov. (International Series of Monographs in Pure and Applied Biology, Division: Zoology, Vol. 30.) Pp. xii +271 . (London and New York: Pergamon Press, Ltd., 1966.) 80s. net.

A

LACK of distinction between fact and fiction characterizes this book. The author's views, for which there is frequently no evidence, are put down as if they were accepted facts. The uninformed reader, sooking information, can have no elue as to what is factual and reliable and what is not. For example, we are told that the Onychophora are a side branch of the Annelida, with no evidence given, and no consideration of the now considerable body of evidence derived from studies on functional morphology. Then we are told what happened to the etenophore-like ancestor of the Articulata when it became a creeper, as if this was an established fact. Further, the Spintheridae are stated to be the most primitive of present-day Polychaeta, but in fact they are highly specialized Amphimomidae, entiroly lacking in the attributes described by Sharov which form the keyston $\theta$ for his view on the origin of the Arthropoda. Spinther possesses polychaete parapodia of a specialized nature, not lobopodia. Tho anterior segments do not become preoral; the "cyclometry" of the adult has nothing to do with etenophore ancestors and is entirely absent in the young worm which has normal worm-like proportions of its body and an almost terminal mouth. Turning to the Arachnida, we find many statements which are unacceptable to workers on this group. That the Pedipalpida originated from the Eurypterida is pure conjecture. Errors of facts, often several per page, occur throughout the book.

Conclusions of others, based on good evidence, are set aside or altered to mean something contrary. For example, it is said that Tiegs and Manton consider that the Myriapoda were derived from the Onychophora. Neither of these authors has ever at any time expressed such a view. Their suggestion that the Myriapoda and Onychophora may have had a common origin, and that they' stand eloser to each other than to any other group of invertebrates, is an entirely different statement, and it is based on facts. Similarly, an extra segment (labial) is pushed into the head of Crustacea by Sharov, in defiance of the abundant good work on crustacean embryology published since 1928. An extra segment is also planted into the onychophoran head; no distinction is made between a statement by Pflugfelder $^{1}$ concerning an embryo of Paraperipatus and the close series of stages belonging to four species of Peripatopsis ${ }^{2,3}$. Ten years of work on hundreds of embryos of Peripatopsis was summarized by a selectod series of accurate reconstructions. It happens to be usual for the cavities of the anterior somites of these Onychophora to arise from several initial spaces which then rapidly fuse. This is no evidence for the existence of multiple anterior segments, and the super. 